\title{
Nanoindentation study on the creep characteristics of high-entropy alloy films: fcc versus bcc structures
}

\author{
Y. Ma ${ }^{\text {a }}$, Y.H. Feng ${ }^{\text {b }}$, Tekalign T. Debela ${ }^{c}$, G.J. Peng ${ }^{\text {a }}$, T.H. Zhang ${ }^{\text {a,* }}$ \\ a College of Mechanical Engineering, Zhejiang University of Technology, Hangzhou 310014, China \\ b State Key Laboratory of Nonlinear Mechanics (LNM), Institute of Mechanics, Chinese Academy of Sciences, Beijing 100190, China \\ c School of Materials Science and Engineering, Northwestern Polytechnical University, Xian 710072, China
}

\section{A R T I C L E I N F O}

\section{Article history:}

Received 23 July 2015

Received in revised form 20 August 2015

Accepted 26 August 2015

Available online 2 September 2015

\section{Keywords:}

High-entropy alloys

Nanoindentation

Creep

Strain rate sensitivity

Activation volume

\begin{abstract}
A B S T R A C T
Using the magnetron sputtering technique, two typical high-entropy alloy (HEA) films namely $\mathrm{CoCrFeNiCu}$ (Al-0) with a face-centered cubic (fcc) structure and $\mathrm{CoCrFeNiCuAl}_{2.5}$ (Al-2.5) with a body-centered cubic (bcc) structure were prepared by alloy targets. The as-deposited HEA films have a columnar-growth mode and nanocrystalline grains. The creep behaviors of both HEA films were systematically investigated by nanoindentation with a Berkovich indenter. The bcc Al-2.5 exhibited a stronger creep resistance than the fcc Al- 0 . In addition, with the increase of holding load and/or loading rate, the creep deformation was significantly enhanced in the fcc Al-0. Interestingly, it was almost history-independent in the bcc Al-2.5. The creep characteristics of HEA films could be related to the distinct lattice structures, which apparently affect the kinetics of plastic deformation. The strain rate sensitivity (SRS) and activation volume of the dislocation nucleation were carefully estimated for both HEA films. In view of the large differences of activation volumes between $\mathrm{Al}-0$ and $\mathrm{Al}-2.5$, we present discussions to explain the observed creep characteristics in HEA films.
\end{abstract}

C 2015 Published by Elsevier Ltd.

\section{Introduction}

Since it was developed by Yeh et al. in 2004 [1], high-entropy alloys (HEAs) have attracted numerous attentions mainly due to the unique structure configuration, and excellent physical and mechanical properties [2-4]. By definition, this new class of metallic alloys has more than five principal elements with equamolar or nearly equamolar ratios. Configuration entropy of mixing (which is equal to $R \ln (N)$, where $R$ is the gas constant and $N$ is the number of elements) would be pretty high in HEAs to stabilize the solid-solution phases of a single face-centered cubic (fcc) or body-centered cubic (bcc) structure [5,6]. However, it does not mean that all the multi-components in equamolar can form solid-solution phases rather than complex ordered intermetallics. In fact, only dozens of compositions with the conventional metallic elements such as $\mathrm{Al}, \mathrm{Co}, \mathrm{Cu}, \mathrm{Cr}, \mathrm{Fe}, \mathrm{Ni}, \mathrm{Nb}, \mathrm{W}, \mathrm{Ti}, \mathrm{V}$, Mo and $\mathrm{Zr}$ were reported hitherto to satisfy the HEA-formation criteria $[7,8]$. The high entropy effect can significantly reduce the free energy of simple solid-solution phases at high temperature, leading to strong thermal stability on both structure and properties in HEAs [9-12]. Owing to the same opportunity for each constituent element to occupy the lattice sites, the mismatch of atomic sizes and chemical bonds can lead to a severe distorted lattice structure in HEAs [13,14]. In HEAs, the strength and plastic deformation are mainly structure type-dependent, i.e., deformation

\footnotetext{
* Corresponding author.

E-mail address: zhangth@zjut.edu.cn (T.H. Zhang).
}

kinetics in the fcc structure could be different from those in the bcc structure $[15,16]$. It has been generally revealed that fcc HEAs have relatively weak strength and great ductility. In contrast, high hardness and limited ductility are the characteristics of bcc HEAs.

Time-dependent plastic deformation, also referred to as creep, has been of great importance and interest from both technological and scientific points of view. However, the creep behaviors of HEAs are rarely studied hitherto and far from understanding. To the author's best knowledge, Chang et al. [17] performed creep tests in (AlCrTaTiZr) $\mathrm{N}_{\mathrm{x}}$ coatings in order to reveal the effect of $\mathrm{N}$ addition, whereas Wang et al. [18] studied the initial creep behavior of a high-entropy-based alloy CoFeNi. In addition, the annealing effect on the creep deformation in a $\mathrm{CoCrFeNiCu}$ HEA film was systematically studied in our previous work [19]. In order to enrich our knowledge of the structure-property correlation in HEAs, the creep characteristics of the fcc and bcc structural samples are very essential. Nanoindentation is the most powerful technology to study the mechanical properties and deformation process of small-sized materials [20]. Nanoindentation technique has already been widely adopted to study creep behaviors of polymers or polymerbased materials [21-23]. Based on nanoindentation, creep behavior of HEAs can be studied at a small region, ignoring the limit of standard size in traditional creep testing. Meanwhile the holding stage could be efficient due to the high accuracy for obtaining the time-dependent plastic deformation. In the present study, two HEA films with components of $\mathrm{CoCrFeNiCu}$ and $\mathrm{CoCrFeNiCuAl} 2.5$ were prepared using magnetron sputtering. The atomic arrangements of these two compositions are 
typical fcc and bcc structures [1,19,24,25], respectively. The roomtemperature creep behaviors were carefully investigated in nanoindentation with a Berkovich indenter. Furthermore, the time-holding experiments were performed at various peak loads with a constant loading rate, as well as constant peak load with various loading rates.

\section{Experimental procedures}

The $\mathrm{CoCrFeNiCu}(\mathrm{Al}-0)$ and $\mathrm{CoCrFeNiCuAl}{ }_{2.5}(\mathrm{Al}-2.5)$ thin films were deposited on a silicon wafer in a DC magnetron sputtering system (Kurt J. Lesker PVD75) at room temperature in pure argon gas. The 2-in. target alloys adopted in the chamber are $\mathrm{Co}_{20} \mathrm{Cr}_{20} \mathrm{Fe}_{20} \mathrm{Ni}_{20} \mathrm{Cu}_{20}$ (at.\%) and $\mathrm{Co}_{13.33} \mathrm{Cr}_{13.33} \mathrm{Fe}_{13.33} \mathrm{Ni}_{13.33} \mathrm{Cu}_{13.33} \mathrm{Al}_{33.33}$ (at.\%) which were prepared from high purity (99.99\%) elements by vacuum casting. The target was installed at the bottom while the silicon wafer was stuck on the sample platform, which is right above the target. The target-to-substrate distance was kept constant at $100 \mathrm{~mm}$. The base pressure of the chamber was kept at about $5 * 10^{-7}$ Torr before deposition, and working argon pressure was set to about $1 \mathrm{mTorr}$. The power on the target was fixed at $200 \mathrm{~W}$ and deposition time was one hour for both films. The film thickness was measured by a surface profilometer (Dektak 150), and was further confirmed from the film cross-section by scanning electron microscope (SEM) (MOI-ZEISS). By means of X-ray energy dispersive spectrometer (EDS) attached on the SEM, the chemical compositions of the samples can be detected. The structures of the samples were detected by X-ray diffraction with $\mathrm{Cu} K_{\alpha}$ radiation. SEM was also used to characterize the surface and cross-section morphologies of the two HEA films.

Nanoindentation experiments were conducted at a constant temperature of $20^{\circ} \mathrm{C}$ on Agilent Nano Indenter G200 with a Berkovich indenter. Prior to the creep testing, hardness and Young's modulus of the two films were studied through continuous stiffness measurement (CSM) technique at a constant strain rate $0.05 \mathrm{~s}^{-1}$. The Poisson's ratio of HEA films was set as 0.3 in the present study. The constant load holding method was used in this work to explore the creep behavior of HEA films. The indenter was held for $500 \mathrm{~s}$ at a series of loading-unloading cycles with different maximum loads 1,3 , and $5 \mathrm{mN}$. In these cases, the loading rate was fixed to $0.5 \mathrm{mN} / \mathrm{s}$. Furthermore, the influence of loading rate on the creep behavior was studied at a constant maximum load $5 \mathrm{mN}$. Four different loading rates namely $0.05,0.1,0.5$ and $0.25 \mathrm{mN} / \mathrm{s}$ were employed. Both the CSM and creep tests were carried out until the thermal drift is reduced to below $0.03 \mathrm{~nm} / \mathrm{s}$. Meanwhile, the drift correction, which was calibrated at $10 \%$ of the maximum load during the unloading process, was carefully performed. To ensure the reliability of creep results, independent measurements in groups of twelve were conducted for each case.

\section{Results and discussion}

The chemical compositions of the as-deposited $\mathrm{Al}-0$ and $\mathrm{Al}-2.5$ films, which are quite close to the alloy targets, are $\mathrm{Co}_{19} \mathrm{Cr}_{19.2} \mathrm{Fe}_{19.2} \mathrm{Ni}_{19.1} \mathrm{Cu}_{23.5}$ and $\mathrm{Co}_{13} \mathrm{Cr}_{12.2} \mathrm{Fe}_{12.4} \mathrm{Ni}_{13.2} \mathrm{Cu}_{17.7} \mathrm{Al}_{31.5}$, respectively. The measured film thickness is $1.45 \mu \mathrm{m}$ for $\mathrm{Al}-0$ and $1.75 \mu \mathrm{m}$ for Al-2.5. Fig. 1 shows the typical XRD patterns of both films that two crystalline solid solution structures are identified: fcc for Al-0 and bcc for Al-2.5. Fig. 2(a) \& (b) shows morphologies of cross section and plane view in Al-0 film, respectively. It has revealed that $\mathrm{Al}-0$ film grows in a typical columnar mode and exhibits a dome-like surface morphology with $40 \mathrm{~nm}-$ $80 \mathrm{~nm}$ spherical grains, in the authors' previous study [19]. Fig. 2(c) \& (d) shows the cross section and plane view of Al-2.5 film. Apparently, the growth manner of Al-2.5 film is almost the same with Al-0 film, which begins with thin dense columns and gradually broadens out. The surface morphology might be growth-dependent, causing a similarity between $\mathrm{Al}-0$ and $\mathrm{Al}-2.5$. The grain size of $\mathrm{Al}-2.5$ is a little larger than that of Al- 0 , which is roughly $50 \mathrm{~nm}-90 \mathrm{~nm}$. This difference could be induced by the different film thicknesses of the two films.

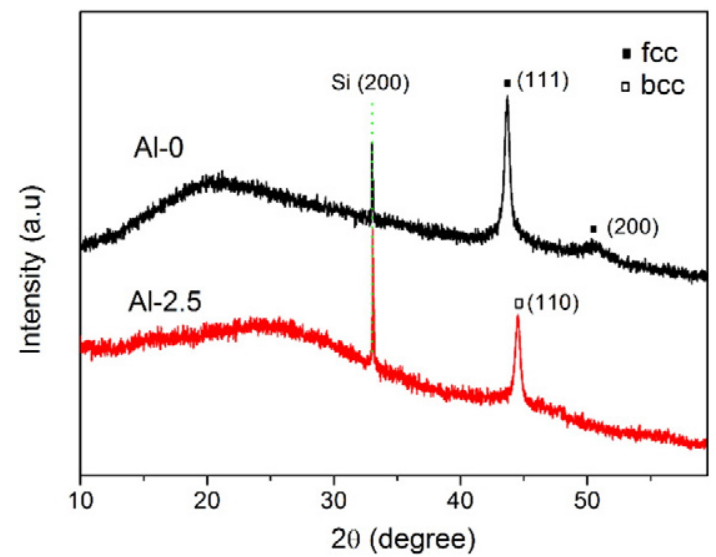

Fig. 1. Typical XRD patterns of the $\mathrm{CoCrFeNiCu}$ and $\mathrm{CoCrFeNiCuAl} 2.5$ high entropy alloy films.

Fig. 3(a) shows the typical Young's modulus and hardness (in the inset) of Al-0 and Al-2.5 films as a function of indentation depth. It is evident that Al-2.5 HEA film has lower Young's modulus but higher hardness in compared with Al-0 sample. The Young's modulus and hardness were obtained at the displacement of $200 \mathrm{~nm}$ for both HEA films. They are $188.5 \pm 3.72 \mathrm{GPa}$ and $7.3 \pm 0.64 \mathrm{GPa}$ for Al-0, and $174.3 \pm$ $2.62 \mathrm{GPa}$ and $9.2 \pm 0.52 \mathrm{GPa}$ for Al-2.5, respectively. Notice that, the obtained Young's modulus and hardness of both films are slightly decreased with the pressed depth. However, this could not be attributed to the indenter "size effect" due to the tip imperfection, or the substrate effect. The Young's modulus and hardness of the standard fused silica remain almost constant in the depth range of $50 \mathrm{~nm}-800 \mathrm{~nm}$, as exhibited in Fig. 3(b) and are about $73 \mathrm{GPa}$ and 9.8 GPa here, which is in good agreement with the previous report [26]. As the indenter pressed into deeper position, the obtained hardness turned to increase at about $375 \mathrm{~nm}$ for Al-0 and $400 \mathrm{~nm}$ for Al-2.5, and gradually approached to the hardness of substrate $\mathrm{Si}$ (14.5 GPa). For the HEA film on $\mathrm{Si}$, the indentation depth for obtaining the "film only" properties was about $20 \%$ of the film's thickness rather than the empirical 10\%-rule. Actually, the decreasing of indentation hardness with depth is well documented for ductile metals. Two possible reasons were suggested to address such a phenomenon that there is a higher local dislocation density [27] and/ or limited available sites [28] for the dislocation nucleation at the smaller depth.

Fig. 4 shows the typical $P$ - $h$ curves of creep tests with various peak loads for the Al-0 and Al-2.5 HEA films, respectively. The creep deformation could be clearly observed at the holding stages. At the onset of holding stage, the severe plastic deformation beneath the indenter has already occurred. This is intrinsically why creep occurs in many highmelting point materials $[29,30]$ by nanoindentation at room temperature. The creep behavior of the HEA films could be more intuitively recognized from the relationship between creep displacements and holding time as plotted in the insets. For authenticity, a creep curve for each maximum load here was averaged from 6-8 effective independent indentations. The creep curves could be divided into two distinct stages: transient creep and steady-state creep. At the transient stage, the creep displacement increases relatively fast but the creep rate drops rapidly. Then the creep displacement tends to increase steadily and almost linearly with time. It can be clearly seen that creep displacement and creep rate of the Al-0 film are enhanced as the peak load increases. While the creep behavior of the Al-2.5 film is nearly independent on the peak load. Fig. 5 summarizes the creep displacements at $1 \mathrm{mN}, 3 \mathrm{mN}$ and $5 \mathrm{mN}$ holding stages, which are $12.5 \mathrm{~nm}, 18.5 \mathrm{~nm}$, $20.6 \mathrm{~nm}$ for Al-0 and $10.4 \mathrm{~nm}, 11 \mathrm{~nm}, 10.8 \mathrm{~nm}$ for Al-2.5. It could be also concluded that $\mathrm{Al}-2.5$ film has a stronger creep resistance than Al-0 film; while creep is a time-dependent plastic deformation and hardness is defined as the resistance to plastic deformation. The 

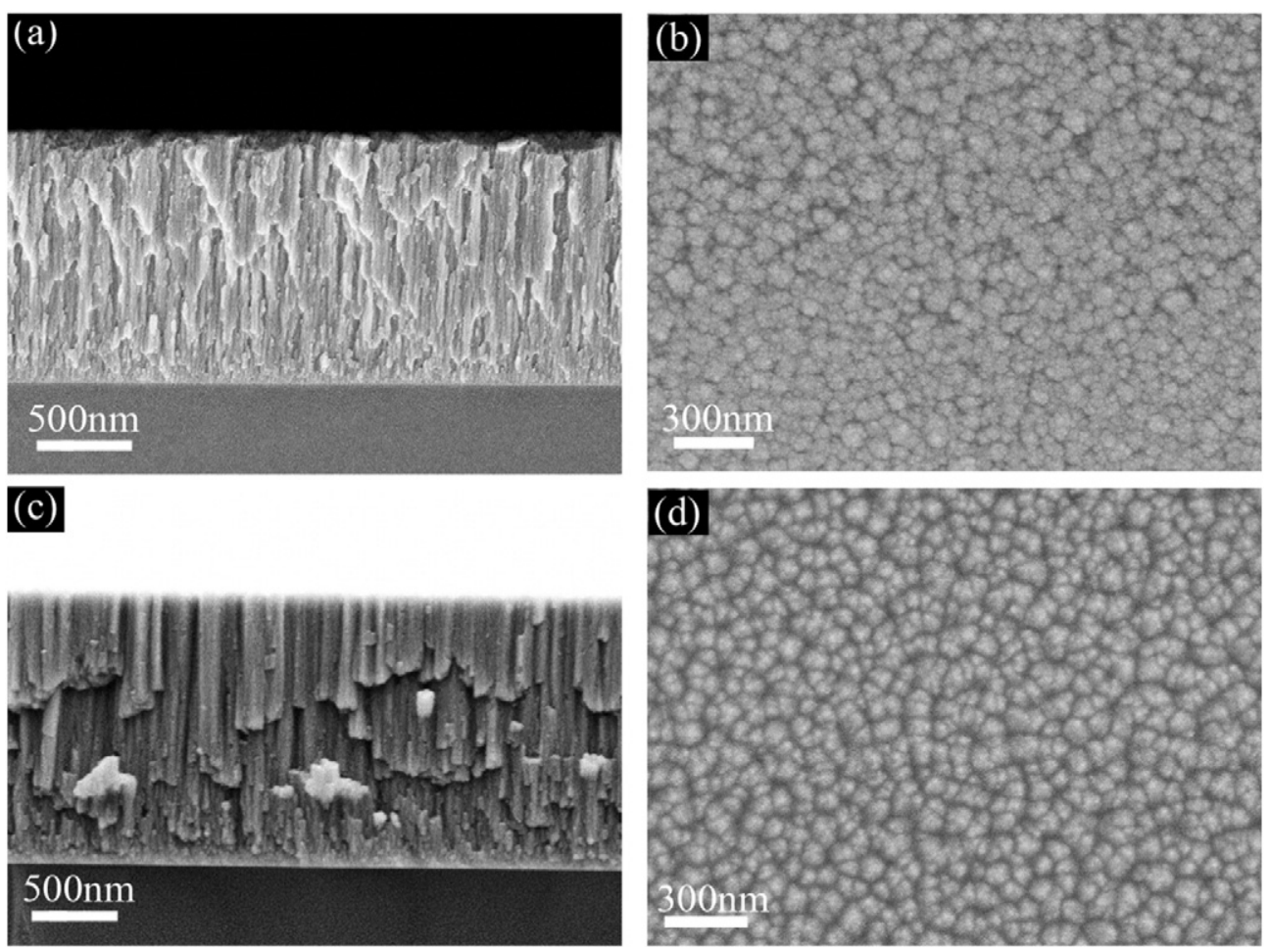

Fig. 2. SEM cross-section micrographs and plane views of the $\mathrm{CoCrFeNiCu}(\mathrm{a}, \mathrm{b})$ and $\mathrm{CoCrFeNiCuAl} 2.5 \mathrm{HEA}$ films (c, d).

enhanced creep resistance by $\mathrm{Al}$ addition could be understandable due to the increased hardness.

Fig. 6(a) and (b) shows the typical $P$ - $h$ curves of $5 \mathrm{mN}$ creep at four loading rates for both HEA films, respectively. At the onset of the holding stage, it is clear that larger indentation depth is required to reach the same load for the slower loading tests in the Al-0 film, indicating enhanced hardness at higher loading rate. While for the Al-2.5 film, such strengthening effect was quite limited as shown in the inset of Fig. 6(b). The corresponding creep curves versus time are shown in Fig. 6(c) and (d), for the Al-0 and Al-2.5 films. Clearly, a faster creep rate could be observed in both transient creep stage and steady-state creep stage by accelerating loading rate in the Al-0 film. It is not surprising that the same effect of loading rate on the creep deformation was already reported in several kinds of metals in nanoindentation [31-33]. Interestingly, the creep behaviors of the Al-2.5 film upon various loading sequences showed little difference, particularly on the steady-state stage and such subtle difference on creep deformation was largely due to the contribution of transient creeps, as shown in the inset of Fig. 6(d). On the case of fast loading sequence, plastic flow could be delayed and released at the holding stage. With regard to slow loading, the time needed to reach the peak load might be considerable for the occurrence of creep deformation, which weakens the creep flow during the holding time. On these accounts, the shorter the holding time, the more obvious loading rate effect on the creep behavior. Thus the same variation trend of the transient creep deformation in both samples might be attributed to the artifacts. On the other hand, the steadystate creep more intrinsically reflects the internal structure and the time-dependent plastic deformation kinetics. Fig. 7 summarizes the creep displacement as a function of loading rates. With the increase of loading rate from $0.05 \mathrm{mN} / \mathrm{s}$ to $2.5 \mathrm{mN} / \mathrm{s}$, the creep displacement had almost doubled in Al-0, i.e., from $11.8 \mathrm{~nm}$ to $21.8 \mathrm{~nm}$. While the creep displacements kept much stable around $10.5 \mathrm{~nm}$ in Al-2.5. It can be concluded that the creep of Al-0 film has a strong correlation with the loading rates. While the creep of $\mathrm{Al}-2.5$ film is essentially historyindependent in nanoindentation. The higher the loading rate, the greater disparity of creep displacements between $\mathrm{Al}-0$ and $\mathrm{Al}-2.5$.
Since the Berkovich indenter is self-similar, the imposed plastic strain and stress distribution during testing are similar at various penetration depths. Notwithstanding, the reported nanoindentation creep deformation was always larger at higher peak loads and/or loading rates whether in crystalline or amorphous alloys. It implies that the creep flow would be affected by the instantaneous plastic deformation at the onset of the holding stage [33]. For example, much more free volume and activated shear transformation zones (STZ) were thought to be generated at higher load and/or fast loading, causing better atomic mobility in metallic glass [33]. In the authors' previous work, creep mechanism of the nanocrystalline $\mathrm{CoCrFeNiCu}$ HEA film was revealed as dislocation dominated [19]. With the addition of a large-sized Al atom, a larger lattice strain effect was identified in the Al-2.5 sample [1]. The growth mode and grain size were almost the same for the bcc and fcc HEA films here, which might be determined by the deposition process. However, the intrinsic plastic characteristics which concern the penetration depth or strain rate in nanocrystalline HEAs are far to be understood. Much more systematic investigations on the morphologies after deformation (or the in-situ investigations) are required to look into the correlation between structure and properties. Since the plastic deformation of metals is thermal-activated, the primary material parameter in revealing deformation mechanism is strain rate sensitivity (SRS) for the applied flow stress [34]. To the author's best knowledge, there is no investigation on the SRS of HEAs in quasi-static strain rate range hitherto. The index of SRS can be obtained [34] by:

$m=\frac{\partial \ln \tau}{\partial \ln \varepsilon}$

where $\tau$ is flow stress and $\varepsilon$ is the strain rate. In a Berkovich nanoindentation process, $\tau$ can be roughly estimated by the empirical conversion $\approx H / 3 \sqrt{3}$. The indentation hardness is defined as $H=\frac{P}{24.5 h_{c}^{2}}$. The equivalent strain rate at the peak load $\varepsilon=\frac{1}{h_{c}} \frac{d h_{c}}{d t}$ can be converted as $\varepsilon=\frac{P}{2 P}$ in the loading rate controlled test [35]. $H_{c}$ is the contact depth, equal to $h-\varepsilon \times P / S$, where $h$ is the recorded indenter displacement 

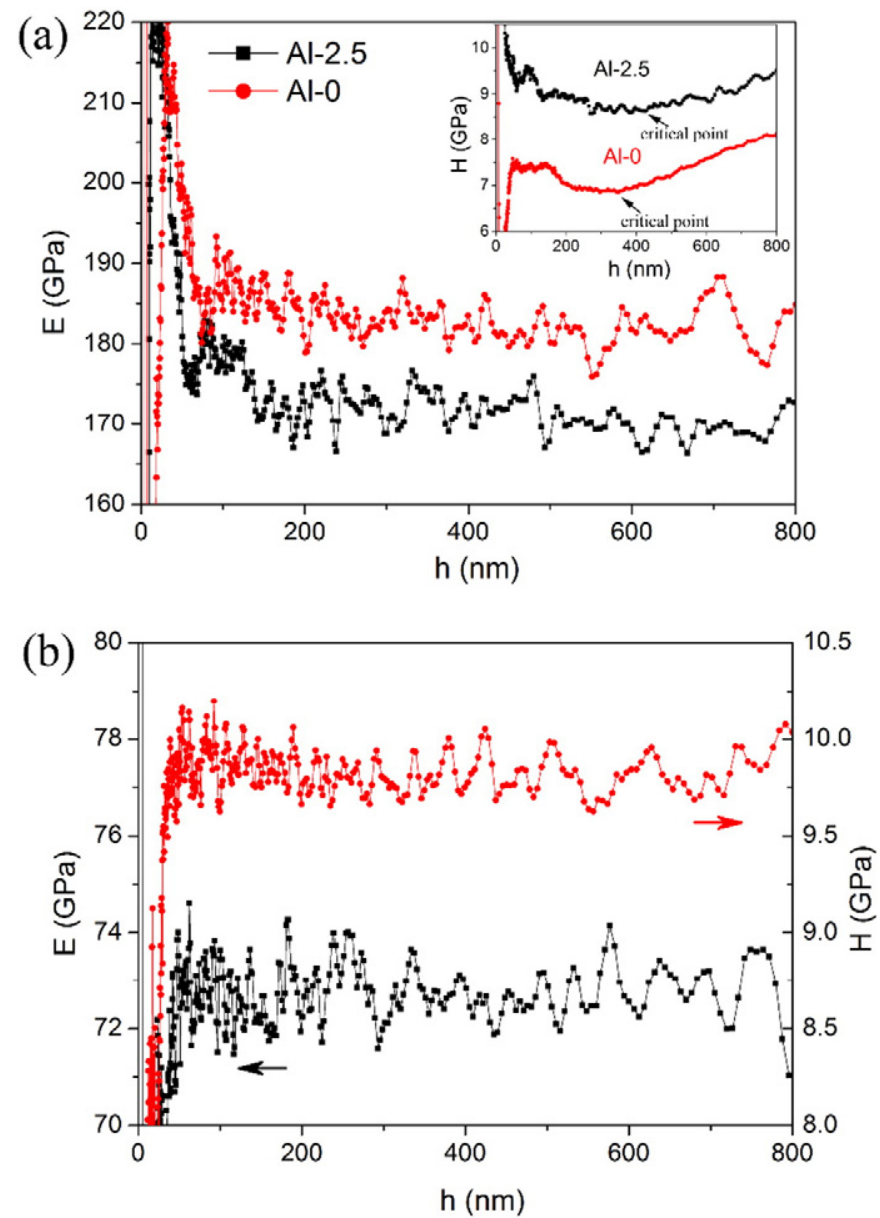

Fig. 3. (a) Typical Young's modulus and hardness (in the inset) as a function of pressed depth by CSM at a constant strain rate $0.05 \mathrm{~s}^{-1}$ for Al-0 and Al-2.5 HEA films. The "substrate effect" appeared until about $375 \mathrm{~nm}$ for Al-0 and $400 \mathrm{~nm}$ for Al-2.5 HEA films, which was indicated by arrow. (b) Young's modulus and hardness of standard fused silica as a function of pressed depth.

and $\varepsilon=0.72$ for a Berkovich tip, and $S$ is the stiffness. In the current study, the stiffness $S$ obtained during the unloading curve of the creep test (Fig. 6) was approximatively employed to calculate the hardness at $5 \mathrm{mN}$. Fig. 8 shows log-log relationships between hardness and equivalent strain rate for the $\mathrm{Al}-0$ and $\mathrm{Al}-2.5$ films. Strain rate sensitivity $m$ then can be deduced from the slope of the linear regression lines, given that $m=0.035$ for the fcc Al- 0 and $m=0.0048$ for the bcc $\mathrm{Al}-2.5$. It has been validated that $m$ increases with decreasing grain size in fcc metals while an opposite trend can be observed in bcc metals [34,36]. The present results for the two HEAs lie in typical levels of fcc and bcc nanocrystalline metals according to previous experimental surveys. A high value of $m$ is always obtained in ductile metals, in which plastic deformation is relatively more non-localized, i.e., against to necking or shear banding in crystal or amorphous alloys [37]. The activation volume for the dislocation nucleation in HEA films can be estimated based on the strain rate sensitivity and shear stress [34], i.e.,

$v^{*}=\frac{k T}{\tau \mathrm{m}}$

where $k$ is the Boltzmann constant and $T$ is the absolute temperature in test. Here the shear stress was deduced by mean hardness of the four loading sequences, $1.48 \mathrm{GPa}$ for $\mathrm{Al}-0$ and $1.70 \mathrm{GPa}$ for $\mathrm{Al}-2.5$. Accordingly, the activation volume was obtained as $0.08 \mathrm{~nm}^{3}$ for Al-0 and $0.51 \mathrm{~nm}^{3}$ for Al-2.5, respectively. From Eq. (2), the activation volume would be the decisive factor for the strain rate sensitivity of metals.
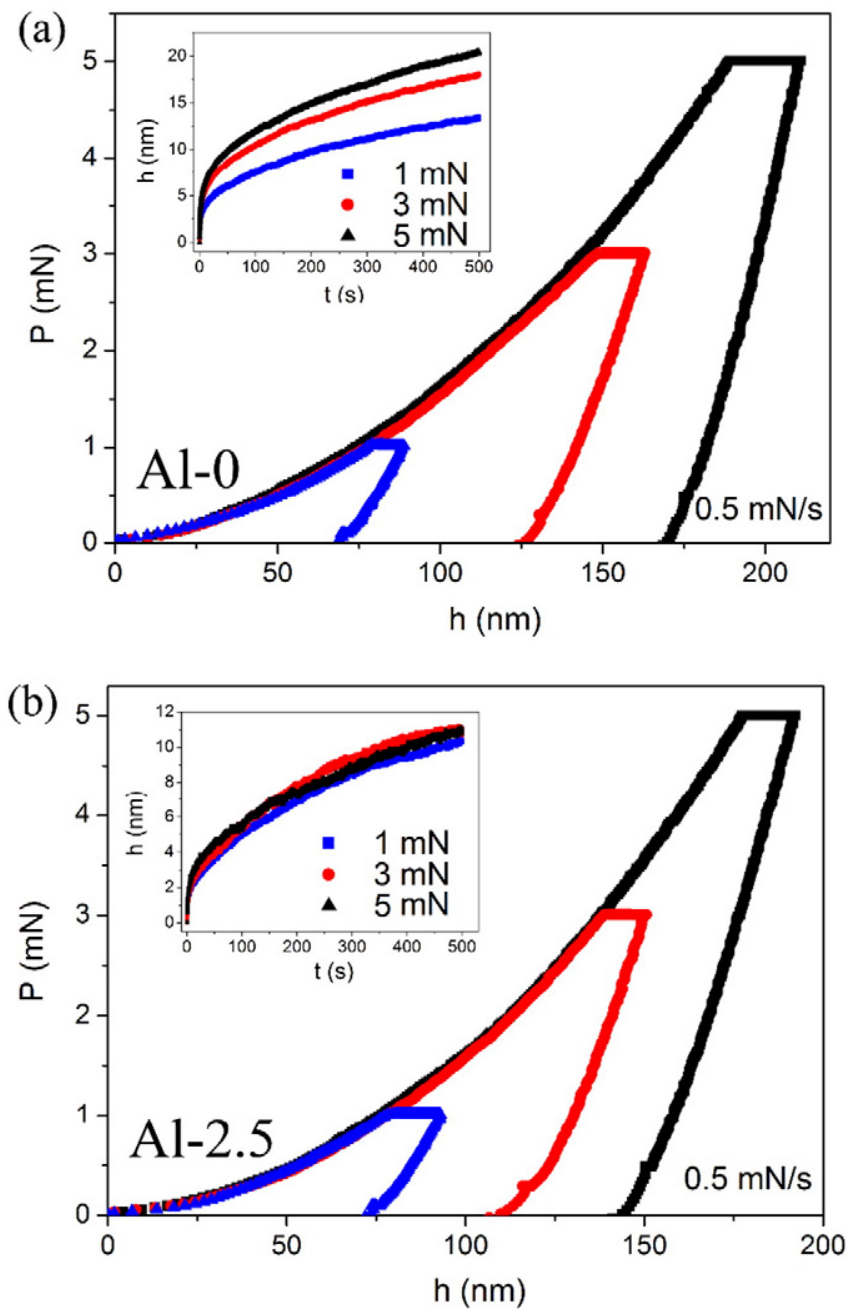

Fig. 4. Representative load-displacement curves and creep displacements during the holding stage (in insets) obtained at three different maximum loads for the $\mathrm{Al}-0$ and Al-2.5 HEA films at a constant loading rate of $0.5 \mathrm{mN} / \mathrm{s}$.

The significant enlargement of activation volume thus predicts a reduction of strain rate sensitivity with the structure transition from fcc to bcc. However, the underlying mechanism for the distinction of the activation volumes between nanocrystalline fcc and bcc HEAs is unknown and out of the scope of this study.

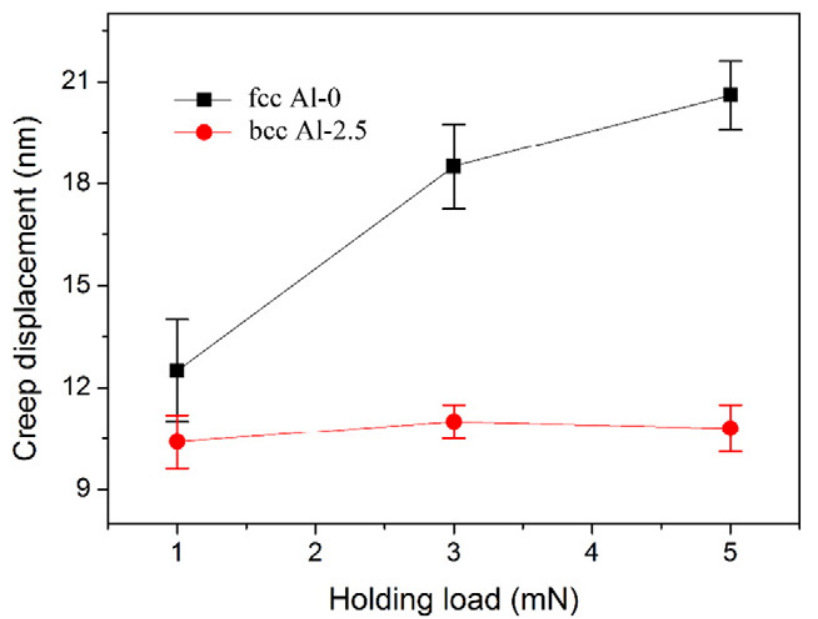

Fig. 5. Creep displacement as a function of the peak load for the Al-0 and Al-2.5 HEA films. 

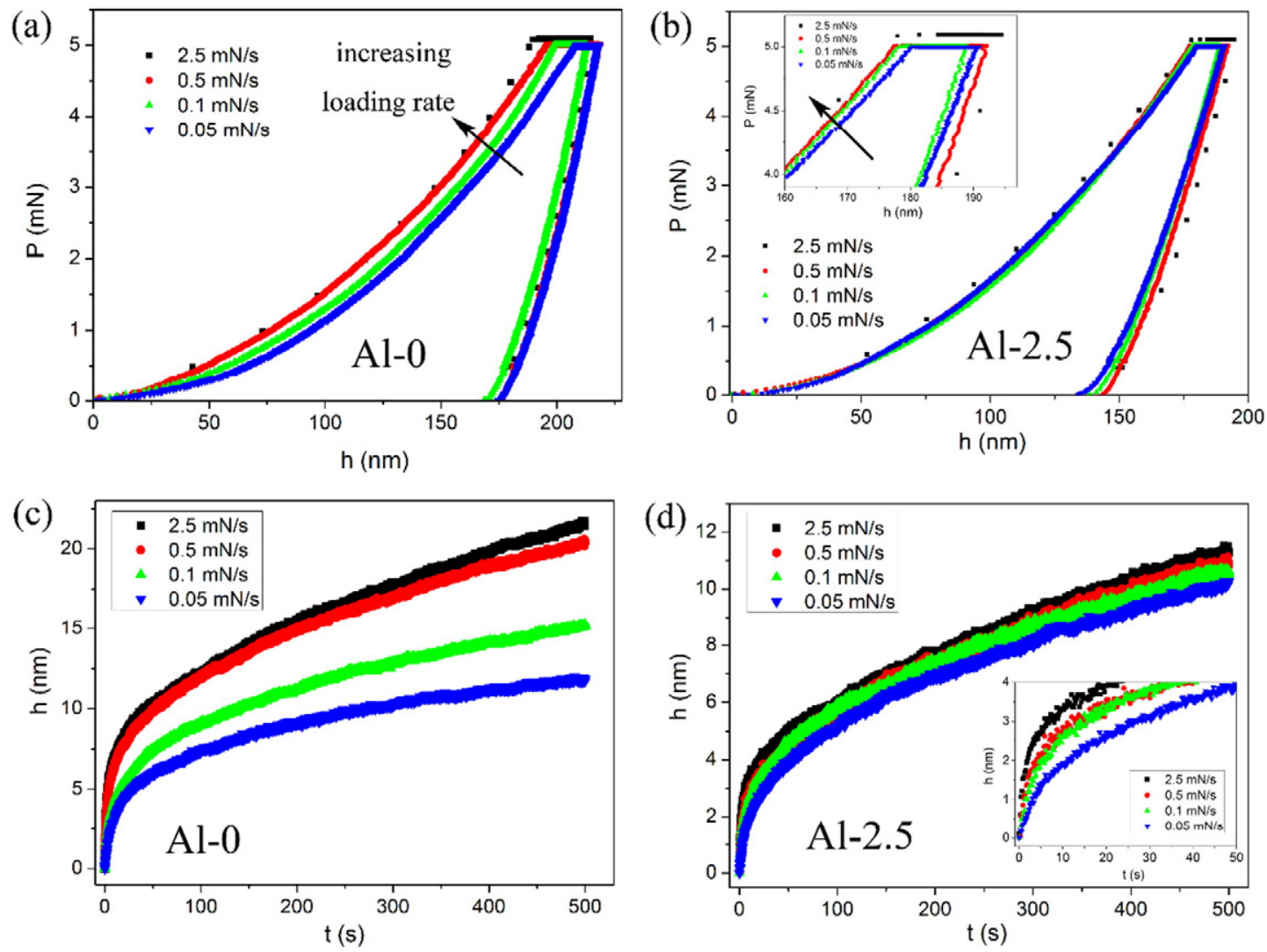

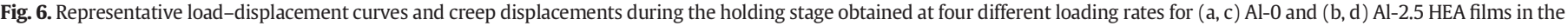
$5 \mathrm{mN}$ creep tests.

In the present study, the focus is on comparison of the lattice structures on the creep behaviors in the nanocrystalline HEA films. From the perspective of nucleation-based rheology, dislocation loops would incubate and grow from the atomic-sized regions at lattice defects. The smaller the activation volume, the easier the nucleation of the dislocation events. The enhanced creep resistance in bcc Al-2.5 could be explained qualitatively that its "flow unit" at the holding stage was hard to be activated, causing less amount of glissile dislocation, and thus the slower creep rate and less pronounced creep deformation. While in fcc Al-0, the "flow unit" would be generated

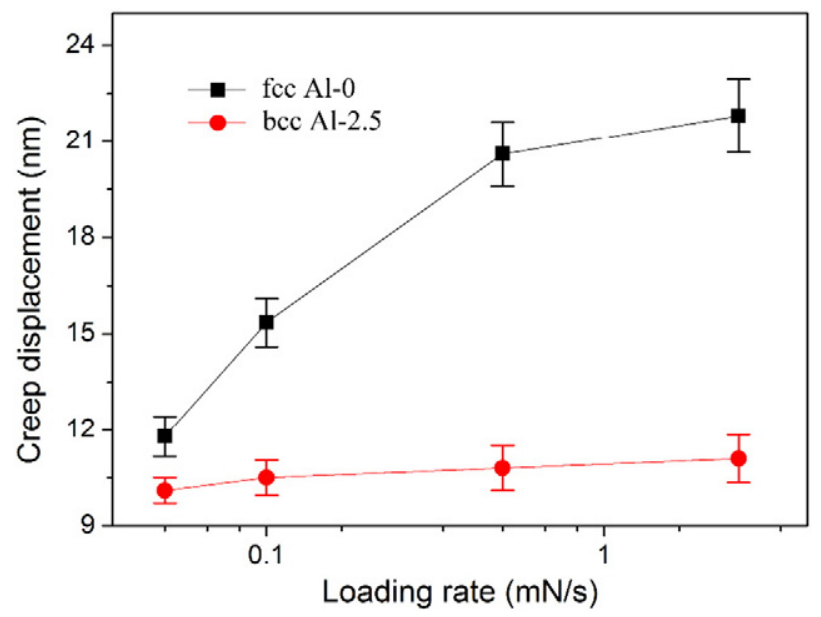

Fig. 7. Creep displacement as a function of the loading rate for the Al-0 and Al-2.5 HEA films. abundantly beneath the indenter, resulting in a good flowability. Furthermore, the activation volume is also indicative to the completely different effects of depth and loading rate on creep deformation in Al-2.5 compared with Al-0. Importantly, the evolution of large-sized activation sites in bcc Al-2.5 can be hardly affected by the small change of surroundings, which would be disturbed with the increase in depth and/or loading rate. In contrast, the nucleation process of dislocation in fcc A- 0 would be much more sensitive to the structure fluctuation (i.e., dislocation or defect density, lattice distortion) and/or stress state, due to the low energy barrier for the activation volume of the

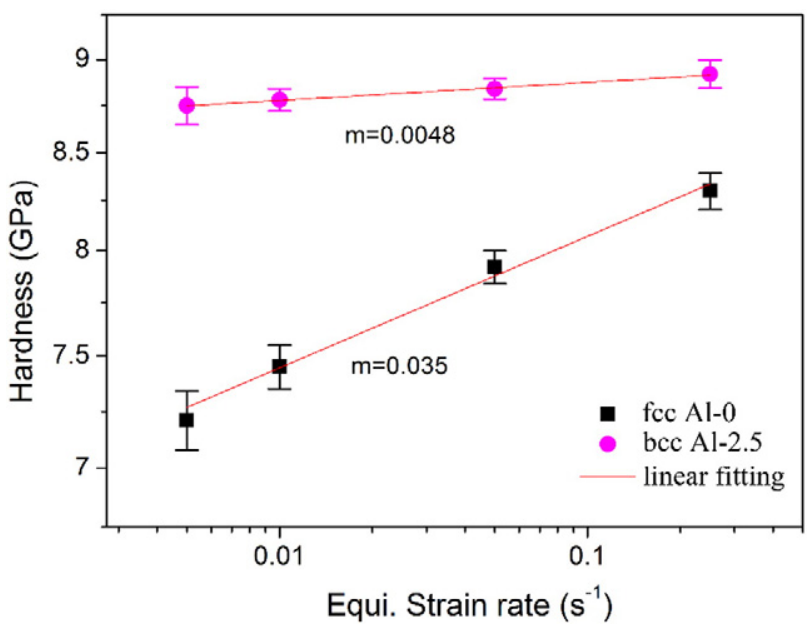

Fig. 8. Nanoindentation hardness versus equivalent strain rates of the HEA films for the calculation of the strain rate sensitivities. 
order of an atomic volume. It is also conceivable that a non-ignorable creep deformation might occur during the loading sequence in Al-0. Such "pre-consumption" explains the weak creep flow at the holding stage with loading rate of $0.05 \mathrm{mN} / \mathrm{s}$ in $\mathrm{Al}-0$.

It should be reiterated that indentation creep is a multi-factor induced time-dependent plastic deformation, which concerns internal structure state, atom mobility and obstacles. Present study intends to reveal the creep characteristics of the nanocrystalline HEAs in light of the strain rate sensitivity and activation volume of the dislocation nucleation. It is noted that shear stress adopted here (converted from indentation hardness) would be much higher than that obtained from uniaxial testing, causing the smaller value in activation volume compared to the reported data in metals.

\section{Conclusion}

In summary, the room-temperature creep behaviors of HEA films with nanocrystalline fcc and bcc structures were investigated by nanoindentation technique. The experimental results showed that creep deformation of the fcc $\mathrm{CoCrFeNiCu}$ film could be promoted by increasing the holding load and/or loading rate. Whereas the bcc $\mathrm{CoCrFeNiCuAl} 2.5$ film exhibited a history-independent creep flow, which was obviously depressed compared to its fcc counterpart. The strain rate sensitivities of both samples were estimated, namely, 0.035 for the fcc Al-0 and 0.0048 for the bcc Al-2.5. Thus the activation volume for the dislocation nucleation in each sample could be determined, which was more than six times larger in bcc HEA $\left(0.51 \mathrm{~nm}^{3}\right)$ than that in fcc one $\left(0.08 \mathrm{~nm}^{3}\right)$. This finding could be intrinsically related to the distinct creep performances between the nanocrystalline fcc and bcc HEA films. The current study provides new insights into the understanding of the time-dependent plastic deformation in HEA at the nanoscale.

\section{Acknowledgments}

The support from the National Natural Science Foundation of China (Grant Nos. 11025212, 11272318, 11302231, 11402233 and
11502235), Zhejiang Provincial Natural Science Foundation of China (Grant No. LQ15A020004) are gratefully acknowledged.

\section{References}

[1] J.W. Yeh, S.K. Chen, S.J. Lin, et al., Adv. Eng. Mater. 6 (2004) 299-303.

[2] Y. Zhang, T.T. Zuo, Z. Tang, et al., Prog. Mater. Sci. 61 (2014) 1-93.

[3] Y. Zhang, T.T. Zuo, Y.Q. Cheng, et al., Sci. Rep. 3 (2013) 1455.

[4] Y.P. Wang, B.S. Li, M.X. Ren, et al., Mater. Sci. Eng. A 491 (2008) 154-158.

[5] J.W. Yeh, Y.L. Chen, S.J. Lin, et al., Mater. Sci. Forum 560 (2007) 1.

[6] P.K. Huang, J.W. Yeh, T.T. Shun, et al., Adv. Eng. Mater. 6 (2004) 74-78.

[7] H. Zhang, Y. Pana, Y.Z. He, et al., Appl. Surf. Sci. 257 (2011) 2259-2263.

[8] X.G. Feng, G.Z. Tang, L. Gu, et al., Appl. Surf. Sci. 261 (2012) 447-453.

[9] V. Dolique, A.-L. Thomann, P. Brault, et al., Surf. Coat. Technol. 204 (2010) 1989-1992.

[10] Y.S. Huang, L. Chen, H.W. Lui, et al., Mater. Sci. Eng. A 457 (2007) 77-83.

[11] T.T. Shun, L.Y. Chang, M.H. Shiu, Mater. Charact. 81 (2013) 92-96.

[12] P.P. Bhattacharjee, G.D. Sathiaraj, M.H. Shiu, J. Alloy. Comp. 587 (2014) 544-552

[13] J.W. Yeh, S.J. Lin, T.S. Chin, et al., Metall. Mater. Trans. A. 35 (2004) 2533-2536.

[14] J.W. Yeh, S.Y. Chang, Y.D. Hong, et al., Mater. Chem. Phys. 103 (2007) 41-47.

[15] Y. Zhang, X. Yang, P.K. Liaw, JOM 64 (2012) 830-838.

[16] Y.J. Zhou, Y. Zhang, Y.L. Wang, et al., Appl. Phys. Lett. 90 (2007) 181904.

[17] S.Y. Chang, S.Y. Lin, Y.C. Huang, C.L.W. Surf, Coat. Technol. 204 (2010) 3307-3314.

[18] Z.J. Wang, S. Guo, Q. Wang, et al., Intermetallics 53 (2014) 183-186.

[19] Y. Ma, G.J. Peng, D.H. Wen, T.H. Zhang, Mat. Sci. Eng. A 621 (2015) 111-117.

[20] A.C. Fischer-Cripps, Nanoindentation, Vol.1, Springer, 2011.

[21] B.D. Beake, G.A. Bell, W. Brostow, et al., Polym. Int. 56 (2007) 773-778.

[22] B.D. Beake, J. Phys. D 39 (2006) 4478-4485.

[23] B.D. Beake, G.J. Leggett, Polym. Int. 43 (2002) 319-329.

[24] H. Zhang, Y. Pan, Y.Z. He, Mater. Des. 32 (2011) 1910-1915.

[25] L. Xie, P. Brault, A.-L. Thomann, et al., Appl. Surf. Sci. 285 (2013) 810-816.

[26] B.D. Beake, J.F. Smith, Philos. Mag. A 82 (2002) 2179-2186.

[27] W.D. Nix, H. Gao, J. Mech. Phys. Solids 46 (1998) 411.

[28] C.A. Schuh, J.K. Masonanda, C. Lund, Nat. Mat. 4 (2005) 617.

[29] S. Syed Asif, J. Pethica, Philos. Mag. A 76 (1997) 1105-1118.

[30] F. Wang, J. Li, P. Huang, W. Wang, T. Lu, Intermetallics 38 (2013) 156-160.

[31] Z. Ma, S. Long, Y. Pan, Y. Zhou, J. Mater. Sci. 43 (2008) 5952-5955.

[32] Z. Cao, Y. Huang, X. Meng, Scr. Mater. 63 (2010) 993-996.

[33] B.-G. Yoo, K.-S. Kim, J.-H. Oh, et al., Scr. Mater. 63 (2010) 1205-1208.

[34] Q. Wei, S. Cheng, K.T. Ramesh, E. Ma, Mat. Sci. Eng. A 381 (2004) 71-79.

[35] D. Pan, A. Inoue, T. Sakurai, et al., Proc. Natl. Acad. Sci. 105 (2008) 14769-14772.

[36] R.J. Asaro, S. Suresh, Acta. Mater. 53 (2005) 3369-3382.

[37] A. Bhattacharyya, G. Singh, K.E. Prasad, et al., Mater. Sci. Eng. A 625 (2015) 245-251. 